\title{
THE POROSITY OF ELECTROPLATED CHROMIUM COATINGS
}

\author{
By W. Blum, W. P. Barrows, ${ }^{1}$ and A. Brenner
}

\section{ABSTRACT}

Various methods for detecting porosity of chromium coatings were found to yield consistent results. Very thin deposits contain round pores. As the thickness is increased the porosity decreases to a minimum, after which an increase in thickness is usually accompanied by the formation of cracks, either parallel or random.

The well-known copper deposition method for detecting the porosity depends upon the fact that copper will deposit only in pores or cracks and not on the chromium. This test was made semiquantitative by measuring either the average apparent current density or the weight of copper deposited in two minutes at $0.2 \mathrm{v}$. The following conclusions are based on such measurements. Their practical significance will be determined by exposure tests now in progress.

The porosity usually increases on standing. This increase is accelerated by heating to $200^{\circ} \mathrm{C}$. Changes in the composition of the solution have no marked effect on the porosity. An increase in the temperature of deposition, for example to $65^{\circ} \mathrm{C}$., instead of the usual temperature of $45^{\circ} \mathrm{C}$., greatly decreases the porosity, especially of thick coatings. At any given temperature the porosity is increased by raising the current density.

Deposits on nickel are less porous than those on other base metals. This difference is at least partly due to the greater ease of securing a bright finish on nickel prior to the chromium plating.

\section{CONTENTS}

I. Introduction

II. Methods of detecting porosity 1. Chemical methods

(a) On iron

(1) Ferroxyl test.

(2) Copper sulphate immersion test.......

(b) On copper and brass.....

(c) On nickel.

2. Copper deposition

3. Comparison of methods

4. Types of porosity

III. Evaluation of the porosity 701

IV. Factors governing porosity 702

1. Preparation of samples

2. Effect of time on porosity at room temperature 702

3. Effect of elevated temperature..... 704

4. Effect of conditions of deposition

(a) Composition of plating bath

(b) Operating conditions

(1) Thickness of deposits ........ 707

(2) Temperature

(3) Current density

(c) The base metal

(1) Composition

(2) Surface condition

V. Conclusions

VI. Bibliography 


\section{INTRODUCTION}

Although chromium plating is very extensively applied to automobiles and other metal products, it is now generally recognized that these deposits are porous and do not furnish much protection against the corrosion of a base metal such as steel. It is therefore the custom to first apply to the steel relatively thick layers of copper and nickel, followed by a thin film of chromium. The chromium serves more for resistance to tarnish than for the protection of the base metal against corrosion.

If the chromium deposits could be made more nearly impervious, their protective value would probably increase, and a smaller thickness of copper and nickel might then be adequate. This paper represents a study of the methods of detecting and evaluating the porosity of chromium coatings, and of the effects of different conditions upon the porosity. The results show that it is possible to produce less permeable deposits at high temperatures. Further observations, including exposure tests, will be required to determine whether this decrease in porosity has any marked effect upon the behavior of the plated metals when in service. This factor will be included in extensive exposure tests that are being conducted by cooperation of this bureau with the American Electroplaters' Society and the American Society for Testing Materials. Pending the completion of such tests, any conclusions based on the results of this investigation must be considered as tentative.

\section{METHODS FOR DETECTING POROSITY}

The porosity of chromium coatings may be detected by various methods.

\section{CHEMICAL METHODS}

In principle it is possible to detect pores or cracks in a metal coating by applying some reagent that will not attack the coating, but will act upon any exposed base metal and yield visible evidence of such action. The composition and concentration of the reagent will vary with the metals involved.

\section{(a) ON IRON}

(1) Ferroxyu Test.-This well-known test has been extensively used to detect porosity of metal coatings, such as copper, nickel, lead, and tin, upon iron or steel. The corrosive agent is usually sodium chloride and attack of the iron is detected by the formation of a blue color with the ferricyanide present in the reagent. This test is applicable only when the metal coating is, under the conditions used, more noble than the iron. It is therefore not applicable to steel coated with zinc or cadmium.

Although chromium in its "active" state is less noble than iron, under most conditions of exposure chromium becomes "passive," and is more noble. Hence the ferroxyl reagent serves to detect pores in chromium coatings on steel. In this work it was found that a reagent containing $10 \mathrm{~g} / 1$ of sodium chloride and $1 \mathrm{~g} / 1$ of potassium ferricyanide yielded within 30 minutes well-defined lines and spots wherever the steel was exposed. If the reagent contains a colloid, such as agar, which is often used in this test, less sharply defined 
patterns are secured. At best the definition is not as good as in some of the other methods to be described.

(2) Copper Sulphate Immersion Test.-When ordinary iron or steel is placed in an acidified copper sulphate solution, copper is deposited "by immersion." It was found that this reaction can be used to detect porosity of chromium coatings on steel, and that well-defined lines or spots appear within 30 minutes.

\section{(b) ON COPPER AND BRASS}

It has been reported by many authors that the ferroxyl test produces red spots wherever copper is exposed through a metal coating. As the red spots are probably due to the formation of cupric ferrocyanide, it seems more logical to apply a ferrocyanide than to depend upon partial reduction of the ferricyanide. Dilute nitric acid attacks copper and brass, but not chromium. A suitable reagent was prepared by dissolving $2 \mathrm{~g} / 1$ of potassium ferrocyanide in dilute nitric acid (10 per cent by volume). Nitric acid of this concentration does not rapidly oxidize ferrocyanide, but it is preferable to add the latter to the nitric acid just before the mixture is used. This reagent produces well-defined spots or lines within 15 minutes wherever copper is exposed.

\section{(c) ON NICIELL}

It was not found possible to develop any reagent that will attack nickel rapidly and not affect chromium. A solution containing $2 \mathrm{~g} / 1$ of dimethylglyoxime in ammonium hydroxide (1-1) slowly produces a pink color wherever nickel is exposed through chromium. As, however, the test requires 12 to 24 hours it is not suitable for inspection purposes.

\section{COPPER DEPOSITION}

It was observed independently by Kyropoulos (1) ${ }^{2}$ and Dubpernell, as quoted by Baker and Pinner (2), that copper does not readily deposit upon chromium. This fact was used by Baker and Pinner (2) and by Baker and Rente (3) as a means of detecting porosity of chromium coatings. They found that when a chromium-plated surface was made the cathode in an acidified copper sulphate solution, copper was deposited only where there were pores or cracks in the chromium. This method was used by them to compare and classify the porosities of various chromium deposits.

In experiments at this bureau it was found that copper can be deposited upon electrodeposited chromium, though it requires a higher potential than to deposit copper on other metals. In order to insure that the copper will deposit only on the exposed base metal and not upon the chromium, it is therefore desirable to control the applied voltage and not the apparent current density as was done by the above authors. The actual current density is indeterminate, as the area upon which the copper is deposited is not known.

It was found that copper is deposited in sharply defined spots or lines within two minutes when a potential of 0.1 to 0.2 volt is applied between a copper anode and a chromium plated cathode that are about $5 \mathrm{~cm}$ ( 2 inches) apart. It is conceivable that copper may deposit in cracks in the chromium that do not extend through to the base

\footnotetext{
2 Numbers in parentheses in the text refer to the bibliography at the end of the paper.
} 
metal. If so, the formation of the copper deposits would not be a true criterion of porosity. To test this possibility a piece of chromiumplated copper was subjected to copper deposition, and the resulting spots and lines of copper were observed and photographed. The chromium was then dissolved off with dilute hydrochloric acid, after which, examination showed the same pattern, which now consisted of ridges of copper adhering to the base metal. The copper deposition test therefore appears to be a reliable measure of the porosity. Subsequently it was found that relatively thick chromium deposits may contain cracks, visible under a microscope, in which copper does not deposit. Presumably such cracks do not extend through to the base metal.

Numerous observations indicate that the resistance of a chromium surface to copper deposition is caused by its passivity. This may be destroyed by treatment with hydrochloric acid, by cathodic pickling or cleaning, or even by vigorous scratching or buffing. Within a short time after such treatments, copper will readily deposit on the chromium itself. On standing in air the passivity slowly returns. This restoration of passivity can be accelerated by making the articles anodic in the acid copper bath for one minute or less with a potential of not more than 0.8 volt. Under these conditions no measurable current passes. The copper deposition method for detecting porosity is valid only on passive chromium. The deposits as removed from the chromium bath and rinsed are in this condition, and the following results apply to such coatings.

\section{COMPARISON OF METHODS}

In order to determine whether the above methods, so far as they are applicable, yield comparable results, deposits of chromium of different thicknesses were made on different base metals and tested by appropriate methods. The results showed similar patterns for companion plates, and hence proved that each of the above methods may be used to detect porosity. As, however, the deposition method is applicable to all base metals and can be made at least semiquantitative, it was employed in all subsequent experiments.

\section{TYPES OF POROSITY}

Figures 1, 2, and 3 illustrate the results obtained by copper deposition. In general thin deposits (up to 0.5 micron or 0.00002 inch) of chromium contain fine holes, roughly circular, which are similar to those in most other electroplated coatings. (Fig. 1.) Thicker deposits (for example 0.5 to 25 microns, or 0.00002 to 0.0001 inch) usually contain cracks, which have also been observed in deposits of other metals, such as platinum, which absorb much hydrogen during: deposition. It was observed that the initial cracks in the chroinium, especially when deposited upon copper and nickel, are parallel to each other, and perpendicular to the direction in which the base metal was last polished. (Fig. 2.) No satisfactory explanation can be offered for this curious phenomenon, which is probably associated with strains set up in the metal surface during the buffing of the base metal. In thick, badly cracked deposits (fig. 3 ) the lines are random and show no preferred orientation. The various types of porosity in chromium deposits have been described by different authors (2), (3), (4). 
B. S. Journal of Research, RP368

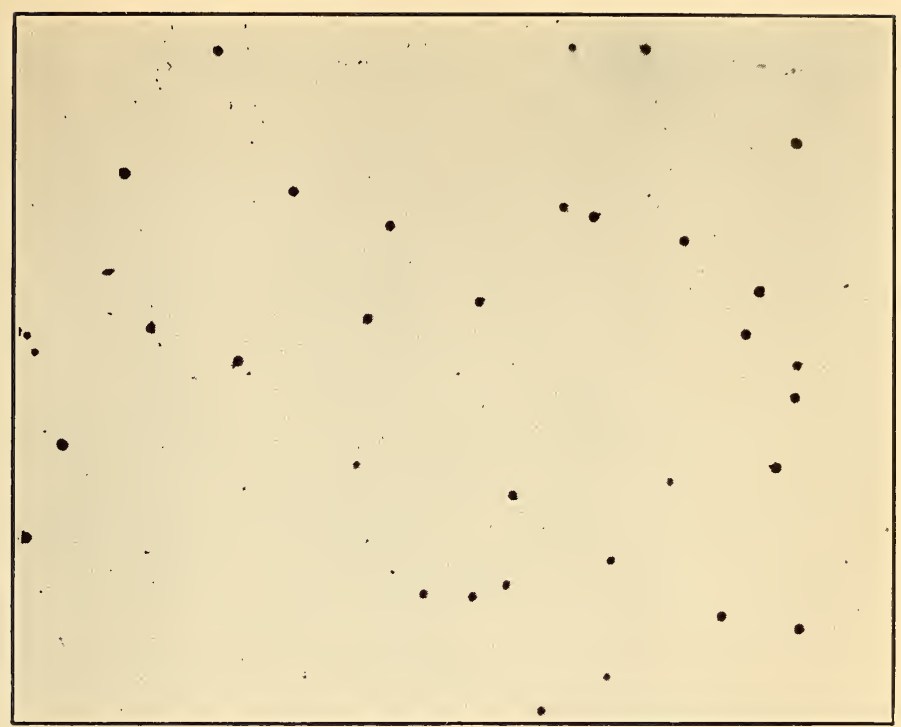

FIgURE 1.-Pores in thin chromium coatings on nickel $(X \quad 40)$

Thickness $=0.14$ micron $(0.000006$ inch). Porosity (expressed in this and other figures as current density in the copper deposition test); $=25 \mathrm{ma} / \mathrm{dm}^{2}$.

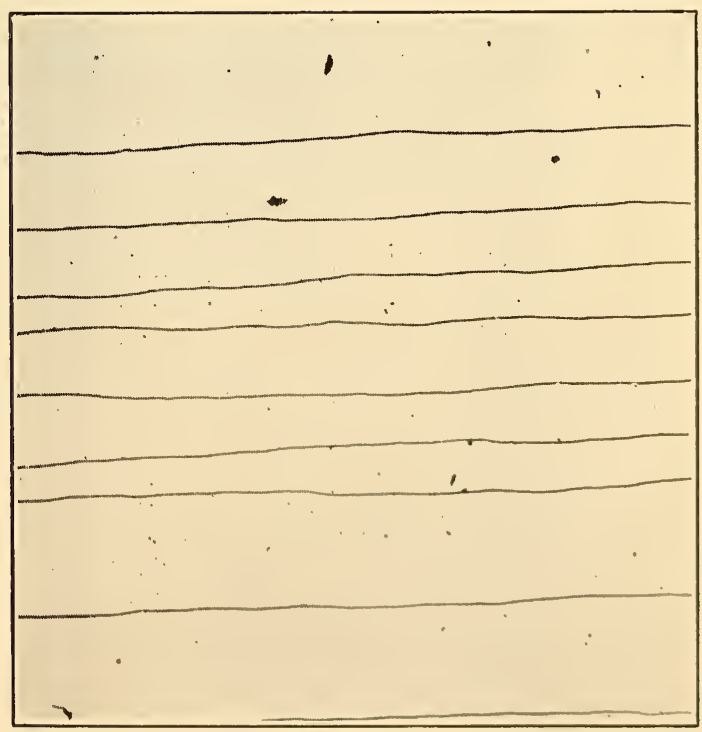

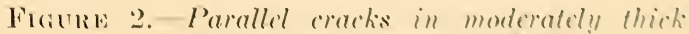
chromium coatings on nickel $(\backslash$ t')

The eracks are perpendientar to the direetion of hast polishing of

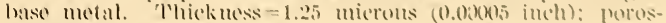
it $\mathrm{y}=1 \mathrm{~s}(\mathrm{)}) \mathrm{m}: \mathrm{a} / \mathrm{dm} \mathrm{m}^{2}$. 
B. S. Journa of Research, RP368

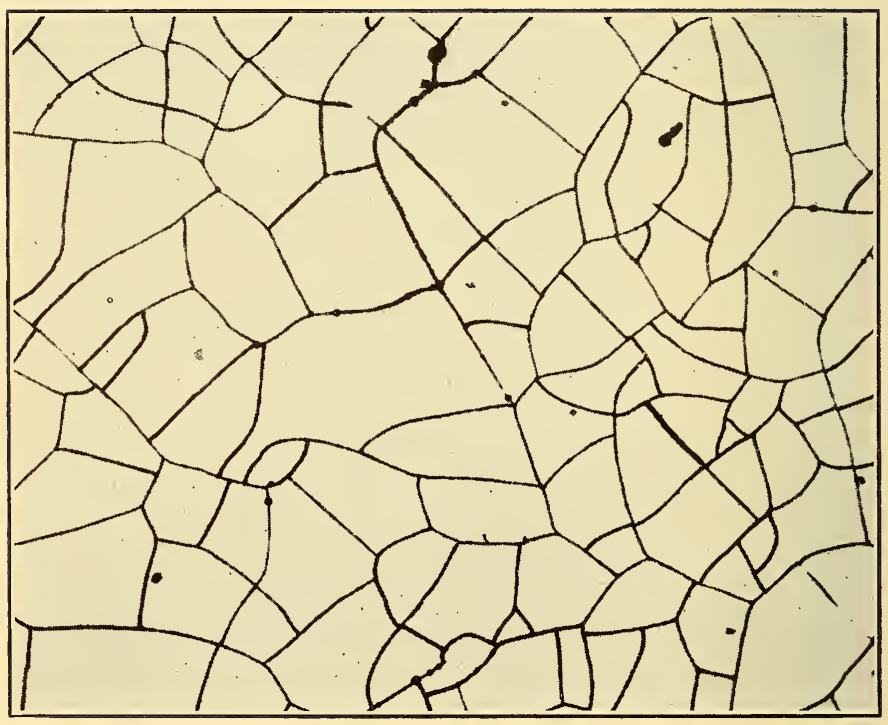

FiguRE 3.-Random cracks in thick chromium coatings on nickel $(\times, 100)$

Thickness $=2.75$ microns $(0.00011$ inch $)$; porosity $=215 \mathrm{ma} / \mathrm{dm}^{2}$. 


\section{EVALUATION OF THE POROSITY}

As the discontinuities in the coatings may consist of either pores or cracks and may vary greatly in number, size, and orientation, it is difficult from visual examination to determine whether better protection would be afiorded by one type of chromium coating than by another. Such a method of test might be more valid if it were possible to measure, or at least to compare, the areas of base metal exposed.

If two electrodes are immersed in an electrolyte at a fixed distance from each other and a constant voltage is applied, the current that passes will increase, but not linearly, if the area of one or both electrodes is increased. In depositing copper at a low potential upon a chromium-plated cathode, the chromium surface is in effect insulated, and current passes only to the exposed base metal, which latter, therefore, represents the effective cathode surface. A change in this area will produce a corresponding change in the current and in the weight of copper deposited in a specified time.

TABLE 1.-Evaluation of porosity of chromium coatings by copper deposition at O.2 v for two minutes

\begin{tabular}{|c|c|c|c|c|c|c|}
\hline \multicolumn{2}{|c|}{ Cr. thickness } & \multirow{2}{*}{ 'Type of porosity } & \multirow{2}{*}{$\begin{array}{l}\text { Average } \\
\text { current } \\
\text { density }\end{array}$} & \multicolumn{3}{|c|}{ Copper deposition } \\
\hline Microns & $\frac{\text { inch }}{100,000}$ & & & $\begin{array}{l}\text { Calcu- } \\
\text { lated }\end{array}$ & Found & $\begin{array}{l}\text { Cathode } \\
\text { efficiency }\end{array}$ \\
\hline $\begin{array}{l}0.13 \\
.13 \\
.25 \\
.25\end{array}$ & $\begin{array}{l}0.5 \\
.5 \\
1.0 \\
1.0\end{array}$ & 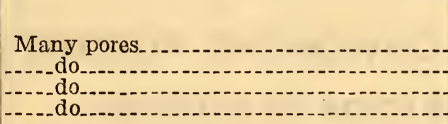 & $\begin{array}{r}m a / d m^{2} \\
365 \\
346 \\
249 \\
205\end{array}$ & $\begin{array}{l}g \\
0.0145 \\
.0137 \\
.0099 \\
.0081\end{array}$ & $\begin{array}{l}g \\
0.0146 \\
.0140 \\
.0100 \\
.0073\end{array}$ & $\begin{array}{r}\text { Per cent } \\
101 \\
102 \\
101 \\
90\end{array}$ \\
\hline $\begin{array}{r}.5 \\
.5 \\
1.0 \\
1.0\end{array}$ & $4^{.2}$ & $\begin{array}{l}\text { Pores and short cracks } \\
\text { Long cracks. }\end{array}$ & $\begin{array}{r}81 \\
100 \\
116 \\
101\end{array}$ & $\begin{array}{l}.0032 \\
.0039 \\
.0046 \\
.0040\end{array}$ & $\begin{array}{l}.0036 \\
.0036 \\
.0052 \\
.0042\end{array}$ & $\begin{array}{r}112 \\
92 \\
113 \\
105\end{array}$ \\
\hline $\begin{array}{r}5.0 \\
5.0 \\
25.0 \\
25.0\end{array}$ & $\begin{array}{r}20 \\
20 \\
100 \\
100\end{array}$ & $\begin{array}{l}\text { Network } \\
\text { do }\end{array}$ & $\begin{array}{l}70 \\
85 \\
54 \\
40\end{array}$ & $\begin{array}{l}.0028 \\
.0034 \\
.0021 \\
.0016\end{array}$ & $\begin{array}{l}.0030 \\
.0032 \\
.0025 \\
.0016\end{array}$ & $\begin{array}{r}107 \\
95 \\
119 \\
100\end{array}$ \\
\hline
\end{tabular}

In the experiments recorded in Table 1, the chromium-plated copper cathodes were 5 by $10 \mathrm{~cm}$ ( 2 by 4 inches) and had a total surface of $1 \mathrm{dm}^{2}$ (16 square inches). Each plate was suspended between two copper anodes of the same size, $5 \mathrm{~cm}$ ( 2 inches) away, in a small glass jar in which the electrodes almost filled the cross section of the copper solution. This contained $200 \mathrm{~g} / \mathrm{l}(27 \mathrm{oz} / \mathrm{gal}$. $)$ of copper sulphate and $75 \mathrm{~g} / \mathrm{l}(10 \mathrm{oz} . / \mathrm{gal}$.$) of sulphuric acid. A constant bath$ voltage of $0.20 \mathrm{v}$. was applied, and the current was read on a milliammeter at intervals of 30 seconds for two minutes. As in most experiments the increase in current from zero was approximately linear, the average current was equal to one-fifth of the sum of the four readings. For practical purposes this is equal to the current at the end of one minute. For longer periods than two minutes, the results were less reproducible. The woight of copper deposited in two minutes was determined from the increase in weight of the cathodes.

The data in Table 1 show that the cathode efficiency for the copper deposition approaches 100 per cent as closely as may be expected from an average current computed from four increasing values. 
Hence either the current (apparent current density) or the weight of copper per unit area may be used as a measure of the porosity. The subsequent results for porosity represent "average current density in milliamperes per square decimeter for a period of two minutes at 0.2 v."

As shown in Table 1 , the results are fairly reproducible. In general, the greatest proportional variations were found in deposits in which the cracking had just started, and in which the metal coating was no doubt in a state of strain. Naturally under such conditions the extent of the cracking would vary in different samples. All subsequent results in this paper represent the average of two or more specimens.

A few efforts were made to estimate microscopically the areas of the copper deposits, and thus to obtain the actual and not merely the relative porosities. The results were not consistent or reproducible. It was evident that even in two minutes' deposition the copper extended considerably beyond the original width of the cracks, sometimes to form a nearly cylindrical wire attached to the copper in the crack. If the deposition was conducted for less than two minutes, some of the finest cracks were not revealed, while deposition for more than two minutes disclosed few, if any, additional cracks, but simply made the copper deposits larger and less distinct. The results of this method of test must therefore be considered as merely semiquantitative, and comparable with each other only when the conditions for the copper deposition are carefully defined and controlled.

\section{FACTORS GOVERNING POROSITY}

\section{PREPARATION OF SAMPLES}

All the specimens used in this phase of the study were flat strips having a total area of $1 \mathrm{dm}^{2}$ (16 square inches). Each was plated with chromium in a small glass jar, in which the specimen almost completely filled the cross section of the solution. A lead anode of the same size was placed about $5 \mathrm{~cm}$ ( 2 inches) from each side of the cathode. The currents through the two anodes were kept equal, so as to obtain uniform deposits on each side of the cathode. The bath was kept at the specified temperatures to $\pm 1^{\circ} \mathrm{C}$. The "standard" solution was prepared from $250 \mathrm{~g} / \mathrm{l}$ of $\mathrm{CrO}_{3}$ and $2.5 \mathrm{~g} / \mathrm{l}$ of $\mathrm{H}_{2} \mathrm{SO}_{4}$. This solution was frequently renewed, and hence did not contain much trivalent chromium.

The cathodes were all buffed or polished before being chromium plated. The nickel plated copper had a coating of nickel about 0.01 $\mathrm{mm}$ (0.0004 inch) thick, which was also polished. The cathodes were introduced into the chromium bath in such a way as to close the circuit. Copper and brass cathodes are likely to be etched and to show increased porosity if this procedure is not followed. The thickness of each deposit was computed from the current density, plating period, and previously determined cathode efficiency.

\section{EFFECT OF TIME ON POROSITY AT ROOM TEMPERATURE}

Preliminary observations showed that the porosity and especially the cracking of chromium deposits increases with time. Hence measurements of porosity made soon after the chromium is deposited 
may not represent the properties of the coatings in service. Corresponding samples were allowed to stand at room temperature in clean air and were tested at intervals. The results in Table 2 show that the most rapid increase in porosity occurs within 24 hours, although the porosity of thick deposits continues to increase for two weeks or more. Thin deposits, which contain pores rather than cracks, do not increase in porosity on standing.

TABLE 2.-Effect of time on porosity of chromium deposits exposed to air at room temperature

[Porosities expressed as apparent average current densities.]

\begin{tabular}{|c|c|c|c|c|c|c|c|}
\hline \multirow{2}{*}{$\begin{array}{c}\text { Experi- } \\
\text { ment }\end{array}$} & \multirow{2}{*}{ Base metal } & \multicolumn{2}{|c|}{ Cr. thickness } & \multicolumn{4}{|c|}{ Elapsed time, days } \\
\hline & & $\underset{\text { crons }}{\mathrm{Mi}-}$ & $\frac{\text { Inch }}{100,000}$ & $1 / 24$ & 1 & 7 & 14 \\
\hline $\begin{array}{ll}1 \\
4 \\
3 \\
3\end{array}$ & $\begin{array}{l}\text { Copper } \\
\text { Brass } \\
\text { Nickel plated } \\
\text { Copper }\end{array}$ & $\begin{array}{r}5.0 \\
5.0 \\
5.0 \\
.5\end{array}$ & $\begin{array}{r}20 \\
20 \\
20 \\
2\end{array}$ & $\begin{array}{r}m a / d m 2 \\
49 \\
20 \\
94 \\
29\end{array}$ & $\begin{array}{r}m a / d m m^{2} \\
118 \\
73 \\
126 \\
15\end{array}$ & $\begin{array}{r}m a / d m^{2} \\
123 \\
83 \\
165 \\
21\end{array}$ & $\begin{array}{r}m a / d m^{2} \\
148 \\
108 \\
136 \\
25\end{array}$ \\
\hline
\end{tabular}

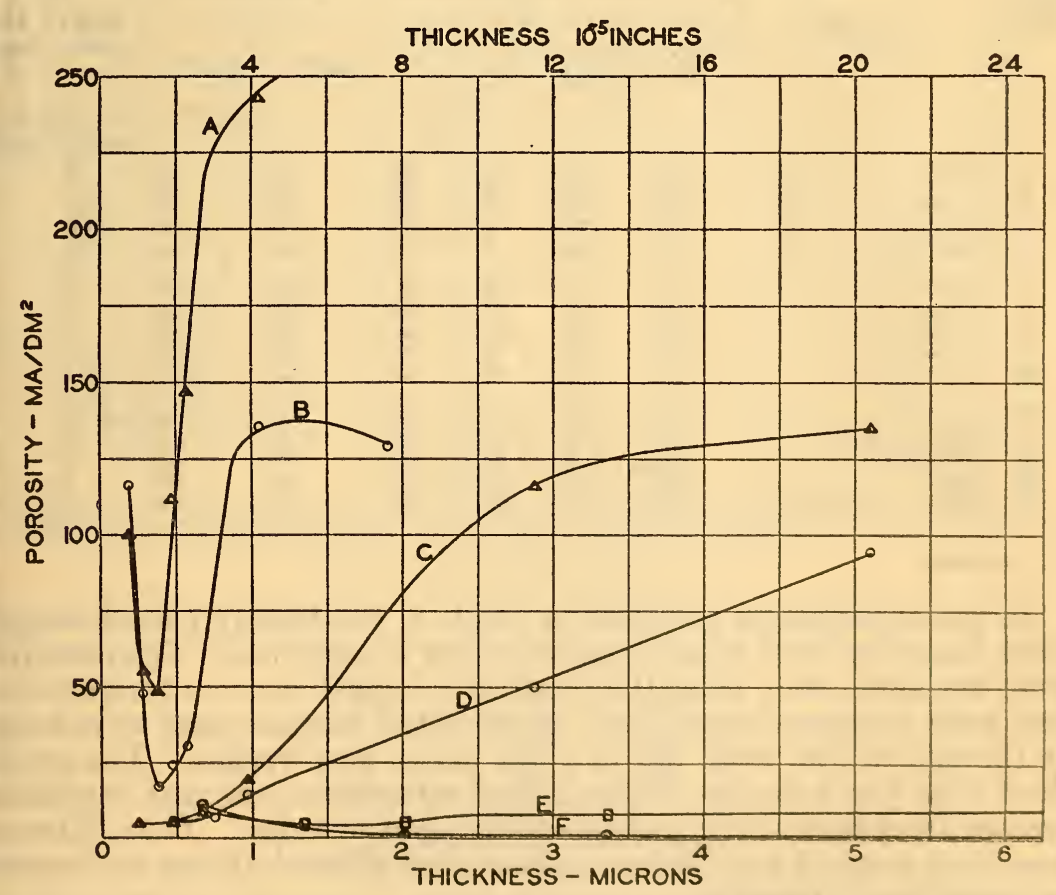

Fugre 4.-Effect of time on porosity

$A, 1$ week; on $\mathrm{Cu}, 45^{\circ} \mathrm{C}$., $10 \mathrm{amp} / \mathrm{dm}^{2}$

B, 1 hour; on $\mathrm{Cu}, 45^{\circ} \mathrm{C}$, , $10 \mathrm{amp} / \mathrm{dm}^{2}$

C, 1 weok; on Ni, $45^{\circ} \mathrm{C}$., $20 \mathrm{amp} / \mathrm{dm}^{2}$

1), 1 hour; on Ni, $45^{\circ} \mathrm{C}$., $20 \mathrm{amp} / \mathrm{dm}^{2}$

F, 1 week; on $\mathrm{Cu}, 65^{\circ} \mathrm{C}$., $60 \mathrm{amp} / \mathrm{dm}^{2}$

F, 1 hour; ou $\mathrm{Cu}, 65^{\circ} \mathrm{C}$., $80 \mathrm{amp}$, $\mathrm{mm}^{2}$

Except as otherwise noted, the subsequent tests were all made after the deposits had aged for one week. The difference in results for one hour and one week is illustrated in Figure 4 for deposits produced 
under widely different conditions. Coatings with low porosity show little difference with time in the actual values, though the proportional change in porosity may be much greater than for more porous samples.

\section{EFFECT OF ELEVATED TEMPERATURE}

It might be expected that heating chromium deposits would accelerate the evolution of hydrogen and the cracking. Heating chromium deposits to change their properties has been suggested by Enos (5) and by Ollard (6). Wirshing (7) recently recommended the heating of chromium-plated metals to $200^{\circ} \mathrm{C}$., and reported that this treatment produced an increased resistance to corrosion in a calcium chloride spray. Herschman (8) found that chromium plated gages heated to $300^{\circ} \mathrm{C}$. showed a marked increase in resistance to wear.

TABLE 3.-Effect of heating upon the porosity of chromium deposits

Heated 30 minutes at $200^{\circ} \mathrm{C} .\left(392^{\circ} \mathrm{F}\right.$.)

\begin{tabular}{|c|c|c|c|c|c|c|c|c|c|}
\hline \multirow{3}{*}{$\begin{array}{l}\text { Ex- } \\
\text { peri- } \\
\text { ment }\end{array}$} & \multicolumn{7}{|c|}{ Conditions of deposition } & \multicolumn{2}{|c|}{ Porosity } \\
\hline & \multirow{2}{*}{ Base metal } & \multicolumn{2}{|c|}{ Cr. thickness } & \multicolumn{2}{|c|}{ Temperature } & \multicolumn{2}{|c|}{ Current density } & \multirow{2}{*}{$\begin{array}{c}\text { Aged } 1 \\
\text { week }\end{array}$} & \multirow{2}{*}{$\begin{array}{c}\text { After } \\
\text { heating }\end{array}$} \\
\hline & & $\begin{array}{l}\text { Mi- } \\
\text { crons }\end{array}$ & $\frac{\text { Inch }}{100,000}$ & ${ }^{\circ} \mathrm{C}$. & ${ }^{\circ} \mathrm{F}$. & $\mathrm{Amp} / \mathrm{dm}^{2}$ & $\mathrm{Amp} / \mathrm{ft}^{2}$ & & \\
\hline $\begin{array}{l}1 \\
2 \\
3 \\
4 \\
5\end{array}$ & $\begin{array}{l}\text { Copper } \\
\text { Brass. } \\
\text { Nickel plate. }\end{array}$ & $\begin{array}{l}0.5 \\
2.5 \\
5.0 \\
5.0 \\
5.0\end{array}$ & $\begin{array}{r}2 \\
10 \\
20 \\
20 \\
20\end{array}$ & $\begin{array}{l}45 \\
45 \\
45 \\
45 \\
45\end{array}$ & $\begin{array}{l}113 \\
113 \\
113 \\
113 \\
113\end{array}$ & $\begin{array}{l}20 \\
20 \\
20 \\
20 \\
20\end{array}$ & $\begin{array}{l}190 \\
190 \\
190 \\
190 \\
190\end{array}$ & \begin{tabular}{|rr}
$m a / d m$ & 2 \\
21 \\
& 177 \\
1148 \\
1108 \\
1136
\end{tabular} & $\begin{array}{r}m a / d m{ }^{2} \\
319 \\
221 \\
146 \\
142 \\
128\end{array}$ \\
\hline $\begin{array}{r}6 \\
7 \\
8 \\
9 \\
10\end{array}$ & $\begin{array}{l}-1 \\
\text { Copper } \\
- \text { do }_{2}\end{array}$ & $\begin{array}{r}.8 \\
.8 \\
2.0 \\
4.0 \\
.5\end{array}$ & $\begin{array}{r}3 \\
3 \\
8 \\
16 \\
2\end{array}$ & $\begin{array}{l}55 \\
55 \\
55 \\
55 \\
65\end{array}$ & $\begin{array}{l}131 \\
131 \\
131 \\
131 \\
149\end{array}$ & $\begin{array}{l}20 \\
35 \\
35 \\
35 \\
35\end{array}$ & $\begin{array}{l}190 \\
325 \\
325 \\
325 \\
325\end{array}$ & $\begin{array}{r}1 \\
11 \\
24 \\
55 \\
4\end{array}$ & $\begin{array}{r}12 \\
192 \\
165 \\
118 \\
54\end{array}$ \\
\hline $\begin{array}{l}11 \\
12 \\
13 \\
14 \\
15\end{array}$ & $\begin{array}{l}\text { Brass } \\
\text { Nickel plate } \\
\text { Brass. } \\
\text { Steel }\end{array}$ & $\begin{array}{r}3.3 \\
.5 \\
.5 \\
2.0 \\
2.0\end{array}$ & $\begin{array}{r}13 \\
2 \\
2 \\
8 \\
8\end{array}$ & $\begin{array}{l}65 \\
65 \\
65 \\
65 \\
65\end{array}$ & $\begin{array}{l}149 \\
149 \\
149 \\
149 \\
149\end{array}$ & $\begin{array}{l}35 \\
35 \\
35 \\
60 \\
60\end{array}$ & $\begin{array}{l}325 \\
325 \\
325 \\
560 \\
560\end{array}$ & $\begin{array}{r}2 \\
13 \\
2 \\
2 \\
6\end{array}$ & $\begin{array}{r}38 \\
120 \\
8 \\
108 \\
45\end{array}$ \\
\hline
\end{tabular}

1 Two weeks.

In the experiments recorded in Table 3 , the freshly plated samples were heated to $200^{\circ} \mathrm{C}$. in an air oven for 30 minutes. The porosities were measured soon after the plates had cooled to room temperature, and were compared with those of unheated samples that were tested at the end of one week (or, in a few cases, two weeks). The results show that the porosity of the heated samples was almost invariably greater than that of the corresponding aged samples. This difference was most marked with those coatings that showed almost no increase in porosity on standing.

From these results it appears that the reported increase in corrosion resistance produced by heating is not due to a decrease in porosity. Wirshing's results may be due to a change in the specific action of calcium chloride on the chromium coating, for example, through an increase in the passivity of the chromium when it was heated in air. The reported increase in abrasion resistance after heating bears no necessary relation to the porosity. It is probably caused by a decrease in brittleness of the chromium when the hydrogen is expelled. 


\section{EFFECT OF CONDITIONS OF DEPOSITION}

(a) COMPOSITION OF PLATING BATH

The most important variables in a chromium bath are the content of chromic acid and the ratio of chromic acid to sulphate. Figure 5 shows that on nickel at $45^{\circ} \mathrm{C} .\left(113^{\circ} \mathrm{F}\right.$.) and $20 \mathrm{amp} / \mathrm{dm}^{2}(186 \mathrm{amp} /$ sq. ft.), with a $\mathrm{CrO}_{3} / \mathrm{SO}_{4}$ ratio of 100 , a change in $\mathrm{CrO}_{3}$ content from 250 to $400 \mathrm{~g} / 1$ (33 to $55 \mathrm{oz}$./gal.) has a slight beneficial effect upon the

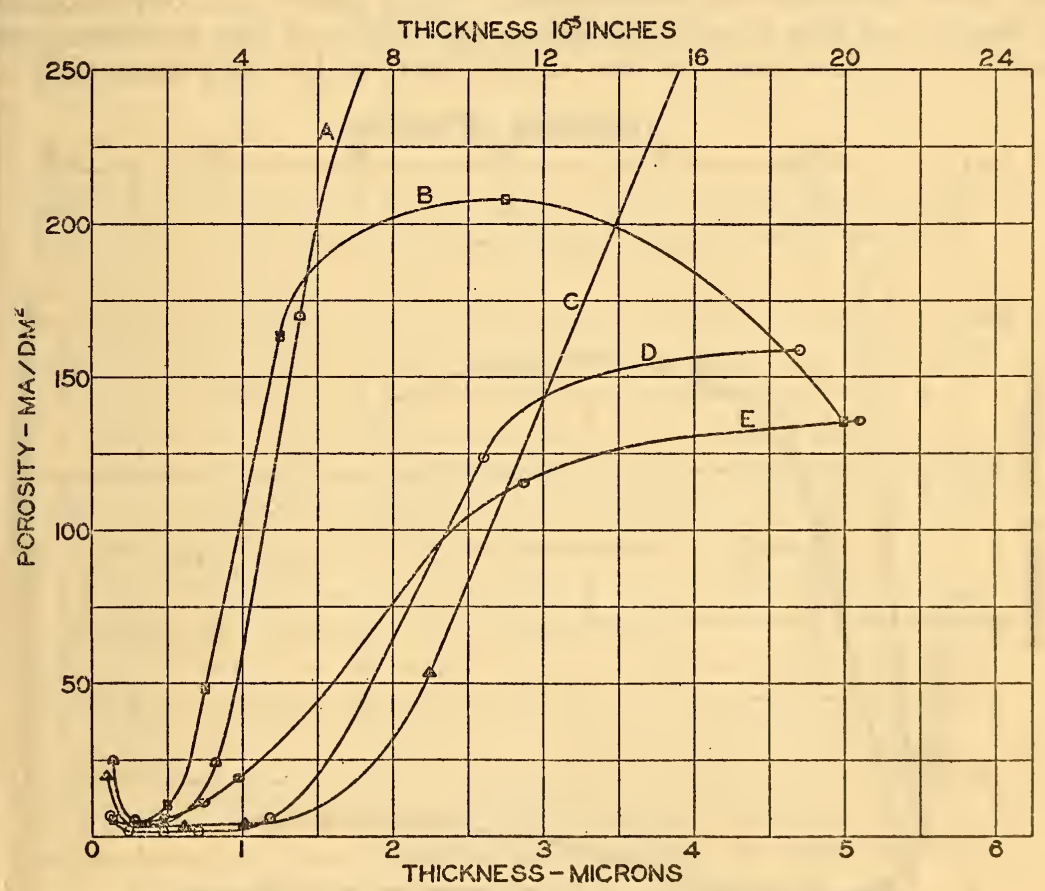

Tigure 5.- Effect of solution composition on porosity. All deposits on nickel at $45^{\circ} \mathrm{C}$. and $20 \mathrm{amp} / \mathrm{dn}^{2}$, aged for one weel.

\begin{tabular}{|c|c|c|}
\hline & $\mathrm{CrO}_{3}$ & $\mathrm{CrO}_{3} / \mathrm{SO}_{4}$ \\
\hline & $g / 1$ & \\
& & \\
& & \\
$\mathrm{~B}$ & 150 & 100 \\
$\mathrm{C}$ & 50 \\
$\mathrm{D}$ & 250 & 100 \\
$\mathrm{E}$ & 400 & 150 \\
& 250 & 100 \\
\hline
\end{tabular}

1 Includes points boy ond the diagram.

porosity of thin coatings. Baker and Rente (3) also found a decrease in porosity when the concentration was increased. More dilute solutions, such as $150 \mathrm{~g} / 1(20 \mathrm{oz} / \mathrm{gal}$. $)$ of $\mathrm{CrO}_{3}$ yield slightly more porous thin deposits and a more sharply defined minimum porosity. As the reproductility is only about 25 per cent, no high accuracy should be attributed to individual points on these and succeeding curves. Their shapes and relative positions have merely a semiquantitative significance. 
An increase in the "sulphate ratio" to 150 produces a decrease in the porosity of thin deposits, while a decrease in the ratio to 50 increases the porosity. It was not found practicable to produce uniformly bright, thin deposits on nickel with a higher sulphate ratio, such as 200, as then some brown spots invariably formed.

No experiments were made upon the effects of trivalent chromium or of iron. It is at least probable that high concentrations of either of these in the plating bath will increase the porosity, especially if they form inclusions in the deposits. Their presence is objectionable on account of the great increase in resistivity of the solutions, and hence their concentrations are usually kept as low as practicable.

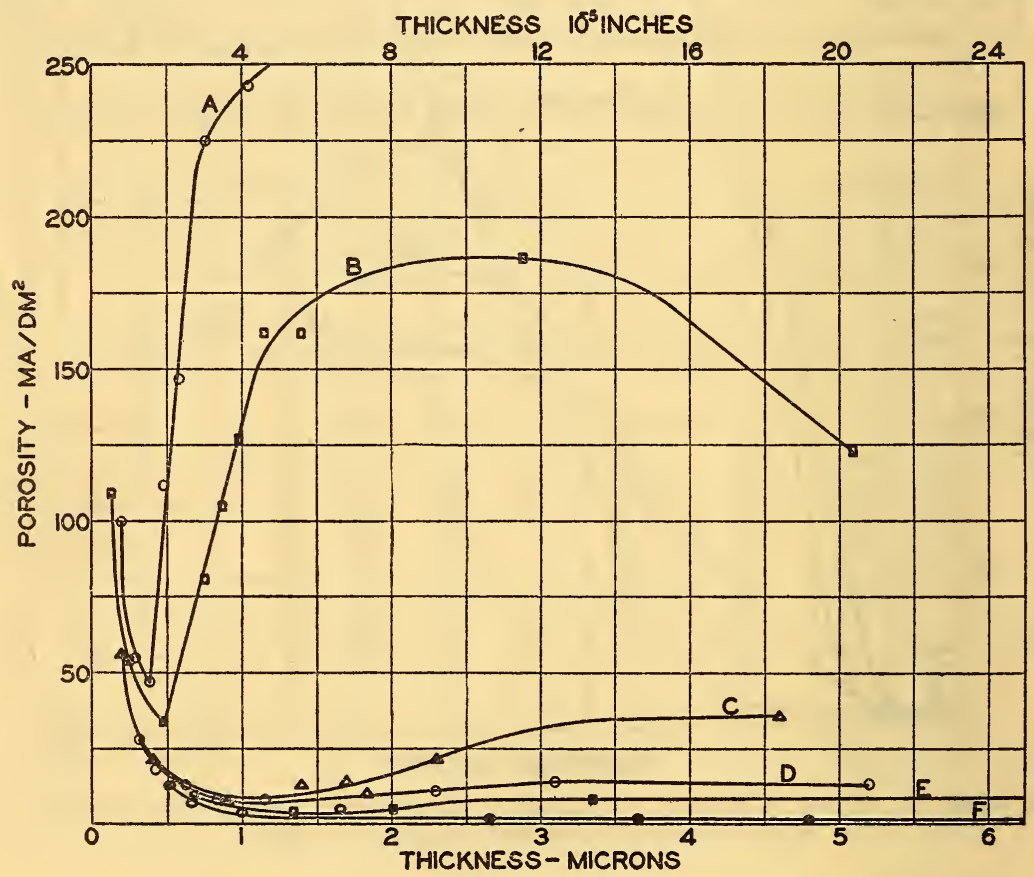

Figure 6.-Porosity of chromium deposits on copper

Solution containing $250 \mathrm{~g} / 1 \mathrm{CrO}$ and $\mathrm{CrO}_{3} / \mathrm{SO}_{4}=100$.

\begin{tabular}{|c|c|c|}
\hline . & $\begin{array}{c}\text { Temper- } \\
\text { ature }\end{array}$ & $\begin{array}{l}\text { Current } \\
\text { density }\end{array}$ \\
\hline $\begin{array}{l}\mathrm{A} \\
\mathrm{B} \\
\mathrm{C} \\
\mathrm{D} \\
\mathrm{E} \\
\mathrm{F}\end{array}$ & $\begin{array}{l}{ }^{\circ} C . \\
45 \\
45 \\
55 \\
55 \\
65 \\
65\end{array}$ & $\begin{array}{c}a m p / d m^{2} \\
10 \\
20 \\
35 \\
20 \\
60 \\
35\end{array}$ \\
\hline
\end{tabular}

(b) OPERATING CONDITIONS

As the temperature and current density must be coordinated in order to obtain bright deposits, and as their effects vary greatly with the thickness, these three factors were simultaneously investigated. The results are shown in Figures 6 to 9 in which all the deposits were bright or nearly so. 
(1) Thickness of Deposits. - The most striking feature of these curves is the pronounced minimum in each curve for deposits made at $45^{\circ} \mathrm{C}$. or lower. The existence of a minimum porosity at a certain thickness has been reported by Baker and Rente (3), and is no doubt partly responsible for the present extensive use of chromium deposits with an average thickness of about $0.0005 \mathrm{~mm}(0.00002$ inch). It should be noted, however, that the minimum porosity under certain conditions may be much greater than that under some other con-

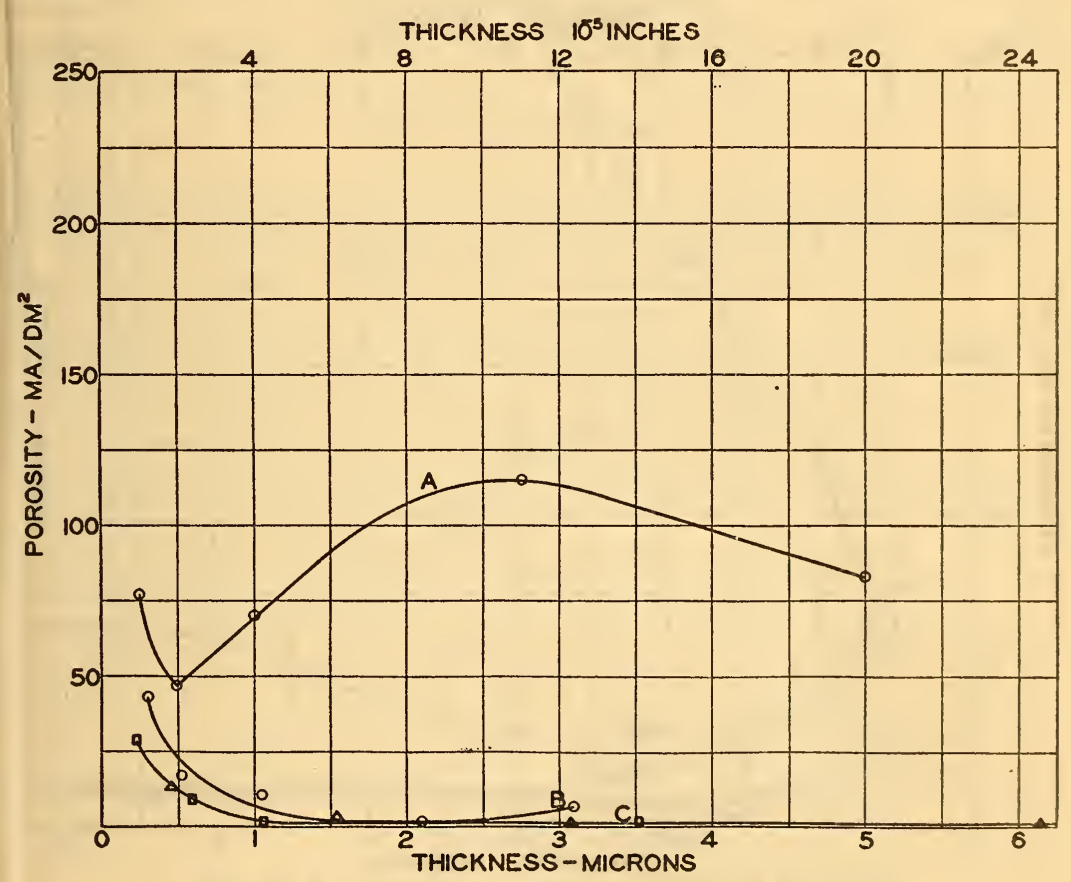

Figure 7.-Porosity of chromium deposits on brass

Solution containing $250 \mathrm{~g} / 1 \mathrm{CrO}_{3}$ and $\mathrm{CrO}_{3} / \mathrm{SO}_{4}=100$.

\begin{tabular}{|c|c|c|}
\hline & $\begin{array}{c}\text { Temper- } \\
\text { ature }\end{array}$ & $\begin{array}{c}\text { Current } \\
\text { density }\end{array}$ \\
\hline & ${ }^{\circ}$ C. & a mp/d $m^{2}$ \\
\hline & 45 & 20 \\
B & 55 & 20 \\
$\mathrm{C}^{2}$ & 65 & 60 \\
& 65 & 35 \\
\hline
\end{tabular}

1 Curves practically coincidont.

ditions, and that it does not necessarily occur at the same thickness. In general, the porosity to the left of the minimum is caused by pores and to the right by cracks. The minimum, therefore, corresponds to the thickness at which most of the pores have been "sealed" and few cracks have appeared.

(2) Temperature.- In general, it was observed that an incrense in bath temperature, accompanied by an appropriate current density to produce bright deposits, yields a minimum porosity that is lower and less sharply marked than at lower temperatures. The curves to 
the left of the minimum are very similar; that is, the conditions of deposition do not greatly change the extent of the pores. The large differences caused by higher temperature become evident in the decreased tendency toward cracking as the thickness is increased. On all the base metals, at $65^{\circ} \mathrm{C}$. $\left(149^{\circ} \mathrm{F}\right.$.) and $35 \mathrm{amp} . / \mathrm{dm} .^{2}(325$ amp./ft. ${ }^{2}$ ) the porosity decreases to a negligible value, which persists as the thickness is increased, even beyond that shown in the figures.

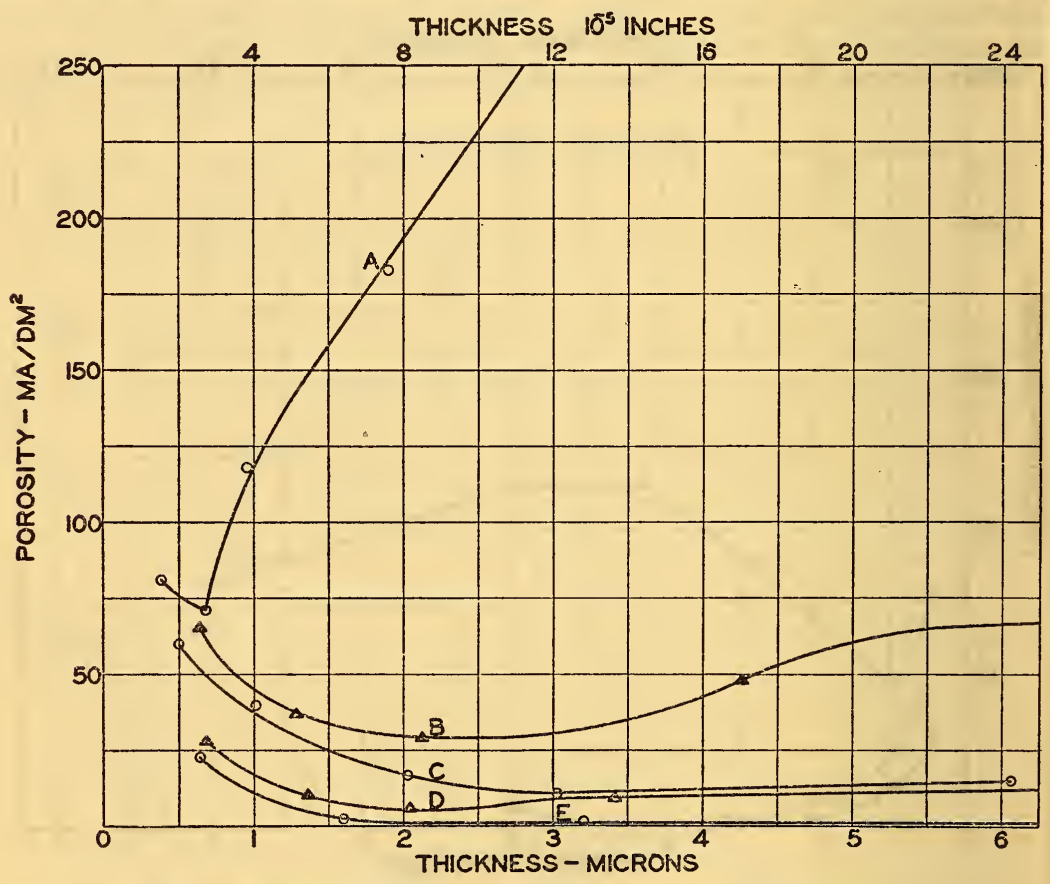

Frgure 8.-Porosity of chromium deposits on steel

Solution containing $250 \mathrm{~g} / \mathrm{l} \mathrm{CrO}{ }_{3}$ and $\mathrm{CrO} / \mathrm{SO}_{4}=100$.

\begin{tabular}{|c|c|c|}
\hline & $\begin{array}{l}\text { Temper- } \\
\text { ature }\end{array}$ & $\begin{array}{l}\text { Current } \\
\text { density }\end{array}$ \\
\hline $\begin{array}{l}\mathrm{A} \\
\mathrm{B}^{1} \mathrm{i} \\
\mathrm{C} \\
\mathrm{D} \\
\mathrm{E}\end{array}$ & $\begin{array}{l}{ }^{\circ} \mathrm{C} . \\
45 \\
55 \\
55 \\
65 \\
65\end{array}$ & $\begin{array}{c}a m p / d m^{2} \\
10 \\
35 \\
20 \\
60 \\
35\end{array}$ \\
\hline
\end{tabular}

1 Includes points beyond the diagram.

Baker and Rente (3) obtained "nearly perfect" plates at $55^{\circ} \mathrm{C}$. $\left(131^{\circ}\right.$ F.). Recently Willink (9) reported that at still higher temperatures (probably approaching $100^{\circ} \mathrm{C}$. or $212^{\circ} \mathrm{F}$.) and current densities exceeding $100 \mathrm{amp} . / \mathrm{dm}^{2}{ }^{2}$ (930 amp./ft. ${ }^{2}$ ) dense deposits were obtained on tools and dies. He did not, however, measure the porosity of the coatings. In this investigation no temperatures above $65^{\circ} \mathrm{C}$. $\left(149^{\circ} \mathrm{F}\right.$.) were used, as most of the deposits produced at that temperature were practically impervious. 
If the cracking of the chromium deposits is due to the evolution of hydrogen that is included in them during deposition, it is reasonable to suppose that the least cracked deposits, for example, those produced at a high temperature, have initially a lower content of hydrogen than the more cracked deposits. No quantitative data are available upon the relation between conditions of deposition and the hydrogen content of chromium. Any lower hydrogen content of the deposits

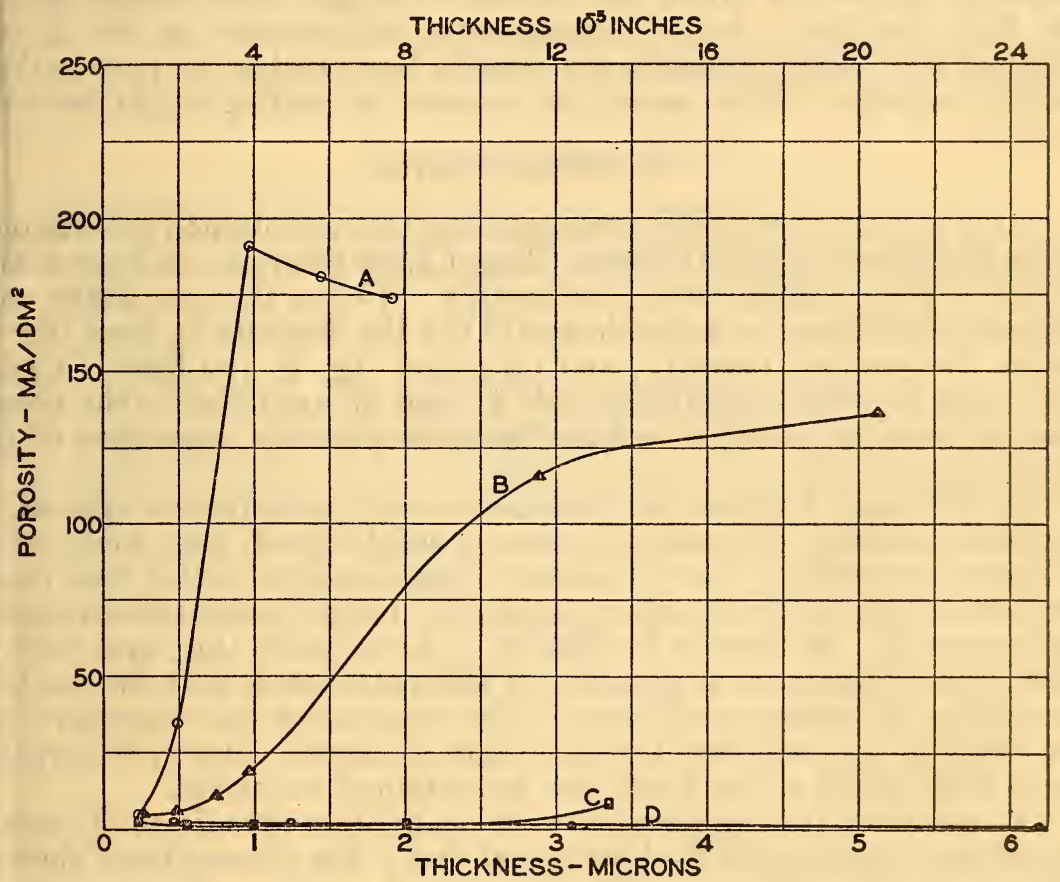

FIGURe 9.-Porosity of chromium deposits on nickel

Solution containing $250 \mathrm{~g} / 1 \mathrm{CrO}_{3}$ and $\mathrm{CrO}_{3} / \mathrm{SO}_{4}=100$.

\begin{tabular}{|c|c|c|}
\hline & $\begin{array}{l}\text { Temper- } \\
\text { ature }\end{array}$ & $\begin{array}{l}\text { Current } \\
\text { density }\end{array}$ \\
\hline $\begin{array}{l}\mathrm{A} \\
\mathrm{B} \\
\mathrm{C} \\
\mathrm{D}\end{array}$ & $\begin{array}{l}{ }^{\circ} C . \\
45 \\
45 \\
55 \\
65 \\
65\end{array}$ & $\begin{array}{c}a m p / d m^{2} \\
5 \\
20 \\
20 \\
60 \\
35\end{array}$ \\
\hline
\end{tabular}

1 Curves practically coincident.

made at higher temperatures is probably caused by lower solubilities of hydrogen in the chromium at the higher temperatures. It certainly is not caused by a change in the cathode efficiency, as the latter is nearly uniform (from about 10 to 15 per cent) for bright deposits. In all cases a large volume of hydrogen is evolved, so that the chromium always has the opportunity to become saturated with hydrogen during its deposition. 
(3) Current Density.-An increase in current density at a given temperature usually increases the tendency toward cracking. As low a current density as will produce bright deposits should, therefore, be used. It was difficult to obtain at $65^{\circ} \mathrm{C}$. $\left(149^{\circ} \mathrm{F}\right.$.) as bright deposits as the best at $45^{\circ} \mathrm{C}$. $\left(113^{\circ} \mathrm{F}\right.$.), although fairly bright deposits were obtained at $65^{\circ} \mathrm{C}$. over a wide current range. If experience shows that deposits produced at a high temperature have a superior protective value, the expense of a light color buffing might be fully justified. A few experiments not recorded in the figures showed that milky deposits are usually less cracked or porous than bright deposits. Here again the expense of buffing might be warranted.

\section{(c) THE BASE METAL}

(1) Composition.-The corresponding curves obtained for different base metals are of similar shapes, though their positions, and especially those of the minima, vary considerably. Under the customary conditions of plating (for example at $45^{\circ}$ C.) the deposits on steel (fig. 8) show the greatest porosity, and on nickel (fig. 9) the least. Under the most favorable conditions $\left(65^{\circ} \mathrm{C}\right.$. and $\left.35 \mathrm{amp} . / \mathrm{dm} .^{2}\right)$, the porosities of coatings above a certain thickness were low regardless of the underlying metal.

(2) Surface Condition.- In most cases chromium is applied to polished surfaces, in order to obtain a bright finish with little or no subsequent buffing. In the above experiments an effort was made to have all the cathode surfaces uniformly bright before the chromium was applied. At best it is difficult to accomplish this, and part of the above differences in porosity on different metals may be due to a variation in surface conditions. The superiority and extensive use of nickel as an undercoat for chromium are largely due to the greater ease with which a fine finish can be obtained on nickel.

No quantitative experiments were made upon the effects of surface defects or roughness of the base metal, but a few observations showed that with chromium as with other metal coatings, the porosity is thereby increased.

\section{CONCLUSIONS}

1. Copper deposition at a low potential serves to detect pores and cracks in chromium coatings on all base metals.

2. If all the conditions during the copper deposition are controlled, either the average apparent current density or the weight of copper per unit area may serve as a semiquantitative measure of porosity.

3. The porosity, and especially the cracking of the chromium coatings, increase rapidly during the first 24 hours' standing, and more slowly for the following few weeks.

4. If the deposits are heated to $200^{\circ} \mathrm{C}$. $\left(392^{\circ} \mathrm{F}\right.$.) for a short time, the cracking is much more pronounced than on specimens aged at room temperature.

5 . The porosity of thin coatings is slightly decreased by an increase in the content of chromic acid.

6. The porosity of thin coatings is slightly decreased by an increase in the $\mathrm{CrO}_{3} / \mathrm{SO}_{4}$ ratio to the maximum value that will yield bright deposits. 
7. Chromium deposits produced at or below $45^{\circ} \mathrm{C}$. ( $\left(113^{\circ} \mathrm{F}\right.$.) show a marked minimum in porosity at a thickness of about 0.5 micron (0.00002 inch).

8. Deposits produced at higher temperatures, such as $55^{\circ}$ or $65^{\circ} \mathrm{C}$. $\left(131^{\circ}\right.$ or $\left.149^{\circ} \mathrm{F}\right)$, have a lower minimum porosity, and the porosity does not increase greatly as the thickness is increased.

9. At any given temperature the porosity is increased by an increase in current density.

10. Under the conditions of plating now commonly used, the porosity is least when the chromium is deposited on nickel and greatest on steel.

\section{BIBLIOGRAPHY}

1. S. Kyropoulos, Z. anorg. Chem., vol. 119, p. 299; 1921.

2. E. M. Baker and W. L. Pinner, J. Soc. Automotive Eng., vol. 22, p. 331; 1928.

3. E. M. Baker and A. M. Rente, Trans. Am. Electrochem. Soc., vol 54, p. 337; 1928.

4. L. E. Grant and L. F. Grant, Trans. Am. Electrochem. Soc., vol. 54, p. $509 ; 1928$

5. G. M. Enos, Trans. Am. Electrochem. Soc., vol. 48, p. 37; 1925.

6. E. A. Ollard, Metal Ind. (London), vol. 27, p. 235 ; 1925.

7. R. J. Wirshing, Trans. Am. Electrochem. Soc., vol. 58, p. 89; 1930.

8. H. K. Herschman, B. S. Jour. Research, vol. 6, p. $295 ; 1931$.

9. A. Willink, Monthly Review, Am. Electroplaters' Soc., vol. 18, No. 4, p. 32; 1931.

Washington, July 21, 1931.

$74280-31-7$ 
